\title{
Aplikasi Learning Management System pada Jenjang Madrasah Aliyah
}

\author{
Nur Istiyan ${ }^{\# 1}$, Rudy Dwi Nyoto*2, Hafiz Muhardi ${ }^{\# 3}$

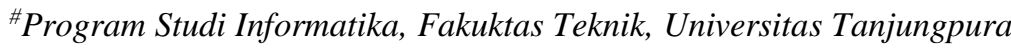 \\ Jl. Prof. Dr. H. Hadari Nawawi, Pontianak 78124 \\ 1nuristiyan.idegmail.com \\ 3 hafiz.muhardi@informatika.untan.ac.id \\ ${ }^{2}$ rudydneinformatika.untan.ac.id
}

\begin{abstract}
Abstrak - Proses pembelajaran yang berlangsung di MAN 1 Kubu Raya memiliki beberapa kendala yaitu adanya keterbatasan waktu dalam penyampaian materi, evaluasi, dan pemahaman siswa yang berpengaruh terhadap hasil belajar siswa. Learning Management System (LMS) sebagai alternatif media pembelajaran untuk keperluan administrasi, dokumentasi, pencarian materi, laporan sebuah kegiatan, pemberian materi-materi pelatihan kegiatan belajar mengajar secara online yang terhubung ke internet. LMS berfungsi mengelola desain pembelajaran yakni membuat materi pembelajaran online berbasis web dan mengelola kegiatan pembelajaran serta hasil-hasilnya. Tujuan penelitian ini adalah untuk menghasilkan aplikasi Learning Management System pada jenjang Madrasah Aliyah serta mengetahui peningkatan hasil belajar siswa menggunakan media pembelajaran yang telah dikembangkan. Metode pengembangan sistem menggunakan konsep model SDLC air terjun (waterfall), konsep tersebut digunakan untuk perancangan sistem. Penelitian ini menggunakan pengujian User Acceptance Test (UAT) dan pre test - post test. Pengujian UAT dilakukan oleh ahli materi, pengajar, dan siswa untuk mengetahui kelayakan media pembelajaran yang telah dikembangkan. Sedangkan pre test - post test dilakukan menggunakan dua kelas untuk mengetahui adanya peningkatan hasil belajar siswa. Hasil penelitian menunjukkan bahwa media pembelajaran yang dikembangkan dinyatakan sangat layak berdasarkan hasil pengujian UAT oleh ahli materi dengan skor $91.42 \%$, pengajar dengan skor $84.95 \%$, dan siswa dengan skor $\mathbf{8 4 . 2 9 \%}$. Hasil analisis data pre test - post test menggunakan skor $N$-Gain terjadi peningkatan belajar siswa yang menggunakan media pembelajaran LMS yakni persentase peningkatan nilai sebesar $\mathbf{4 0 . 7 9 \%}$ dengan kriteria sedang (medium) dimana skor $\mathrm{g} \geq 0.3$, sedangkan siswa yang menggunakan media pembelajaran tradisional yakni $15.93 \%$ dengan kriteria rendah (low) dimana skor $\mathrm{g}<\mathbf{0 . 3}$.
\end{abstract}

Kata kunci: Learning Management System (LMS), Desain Pembelajaran, System Development Life Cycle (SDLC), User Acceptance Test, Pre Test - Post Test

\section{Pendahuluan}

Pembelajaran merupakan kegiatan yang mengandung interaksi antara guru dengan peserta didik dan timbal balik yang berlangsung dalam situasi edukatif untuk mencapai tujuan belajar. Proses pembelajaran dalam sistem pendidikan merupakan suatu sistem yang utuh dan tidak terpisahkan dengan komponen pembelajaran yaitu input (peserta didik) dan dengan bantuan instrumental input, output dan outcome [1]. Berdasarkan hasil wawancara yang dilakukan kepada pengajar atau guru MAN 1 Kubu Raya, pelaksanaan pembelajaran dilaksanakan di dalam kelas menggunakan metode pembelajaran secara langsung yakni dengan metode ceramah baik dengan lisan maupun tulisan menggunakan buku pelajaran, serta metode pembelajaran lebih kepada penugasan.

Adapun perangkat pembelajaran yang digunakan oleh pengajar yaitu Kurikulum 2013 dengan Rencana Pelaksanaan Pembelajaran (RPP) dan rubik penilaian yang mengacu pada silabus. Sumber belajar menggunakan buku pelajaran dengan materi yang diambil dari Standar Kompetensi Lulusan (SKL) mengikuti Kompetensi Isi (KI) dan Kompetensi Dasar (KD). Aspek penilaian yang digunakan adalah pengetahuan dan keterampilan dengan bentuk evaluasi berupa tes tulis dan kinerja atau praktek yang dibuat dengan indikator pencapaian kompetensi, kemudian dinilai berdasarkan aspek-aspek penilaian. Pengajar atau guru MAN 1 Kubu Raya menyatakan bahwa terdapat beberapa kendala yang dihadapi saat pembelajaran berlangsung diantaranya keterbatasan waktu dalam penyampaian materi, evaluasi, dan pemahaman siswa yang berpengaruh terhadap hasil belajar siswa yakni sebanyak $60 \%$ siswa memperoleh nilai rendah, sisanya menengah, dan hanya beberapa saja yang memperoleh nilai tinggi.

Selain itu, hasil dari angket siswa menginginkan adanya media pembelajaran yang lebih interaktif sehingga menarik minat siswa dalam belajar agar dapat membantu memahami materi yang disampaikan. Berdasarkan hasil wawancara kepada pihak sekolah menyatakan bahwa saat 
ini belum tersedia media pembelajaran lain yang digunakan di sekolah, sehingga diperlukan media pembelajaran yang dapat membantu proses pembelajaran dalam upaya peningkatan hasil belajar siswa. Salah satu alternatif yang diajukan untuk mengatasi permasalahan tersebut adalah dengan memanfaatkan perkembangan Teknologi Informasi dan Komunikasi (TIK) dalam pembelajaran yang lebih interaktif, dan mampu memberikan beragam sumber belajar yang dapat diakses setiap saat oleh siswa sehingga dapat menarik minat belajar siswa yakni dengan membangun aplikasi Learning Management System (LMS) berbasis Web-Enhanced Learning. Model pembelajaran ini menggunakan teknologi internet sebagai sumber belajar tambahan yang bertujuan untuk memperkaya pengetahuan peserta didik yang memperoleh pembelajaran di kelas [2]. Penggunaan aplikasi Learning Management System ini diharapkan dapat membantu proses pembelajaran dalam upaya peningkatan hasil belajar siswa.

\section{URAIAN PENELITIAN}

\section{A. Literature Review}

Literature lain tentang Learning Management System (LMS) sebelumnya sudah pernah dilakukan oleh beberapa peneliti, salah satunya adalah Shandra Wahyuliany dan Lusia Rakhmawati, yang merancang media pembelajaran e-learning berbasis internet web enhanced course menggunakan software Moodle pada mata pelajaran teknik listrik. Sistem ini dirancang dapat menampilkan materi yang berisi beberapa simulasi, download materi dalam format pdf, video, dan latihan soal [3].

Penelitian lainnya dilakukan oleh Ardian Asyhari dan Rahma Diani, yang mengembangkan web-blogs dengan metode $\mathrm{R} \& \mathrm{D}$ prosedur 4D (define, design, develop, disseminate) yang dapat mendukung Web Enhanced Course (WEC) agar menunjang pembelajaran Fisika Dasar 1 materi Gerak Dua Dimensi. Spesifikasi pada WEC yang dikembangkan menekankan pada web yang memungkinkan terjadinya komunikasi interaktif antara dosen dan mahasiswa, baik secara individu maupun kelompok, serta dapat menjadi alternatif belajar secara online [4].

Kemudian penelitian dilakukan oleh Putra Yoga Dwiangga Mustafa, yang merancang aplikasi Learning Management System berbasis web dengan menggunakan model SCORM (Shareable Content Object Reference Model). Sistem yang dirancang memiliki beberapa pengolahan data meliputi forum, penyimpanan materi (upload dan download), latihan soal atau tugas, dan laporan siswa (rekapan nilai), serta penyimpanan kemampuan object untuk berbagi meliputi gambar, dokumen, video, audio, dengan menggunakan model SCORM dilakukan dalam satu lokasi yang sama dengan pembeda dari tiap-tiap object [5].

Dalam penelitian ini, aplikasi Learning Management System pada jenjang Madrasah Aliyah dibangun dengan beberapa fitur untuk mendukung pembelajaran yang dapat diakses secara online, diantaranya terdapat fitur materi atau bahan ajar berupa konten (video dan audio) serta file dalam format pdf., doc., ppt., dan lain-lain. Selain itu terdapat menu kuis online berupa pilihan ganda dan essay, tugas kelompok, menu upload tugas, menu bank soal, menu penilaian dan rekapan nilai siswa, menu analisis soal, menu analisis pencapaian kompetensi dasar, link ke website lain, pengumuman, komentar, dan chat. Fitur-fitur yang disediakan ini lebih spesifik dan disesuaikan berdasarkan Rencana Pelaksanaan Pembelajaran (RPP) MAN 1 Kubu Raya.

\section{B. Definisi E-Learning}

E-Learning adalah cara pembelajaran dengan menggunakan aplikasi elektronik seperti web based ataupun desktop dalam bentuk CD-ROM. E-Learning juga dapat dikatakan sebagai pendidikan yang dilakukan melalui internet atau jaringan komputer. Sehingga, dapat disimpulkan bahwa e-learning merupakan sistem pembelajaran dengan media elektronik untuk meningkatkan proses belajar mengajar dengan media internet, jaringan computer, maupun komputer [5].

\section{Fungsi E-Learning}

Fungsi pembelajaran elektronik atau e-learning terhadap kegiatan pembelajaran di dalam kelas (classroom instruction), yaitu sebagai suplemen yang sifatnya pilihan atau opsional, pelengkap (komplemen), atau pengganti (substitusi) [6]. Fungsi pembelajaran elektronik atau $e$ learning terhadap kegiatan pembelajaran di dalam kelas (classroom instruction) digambarkan pada Gambar 1.
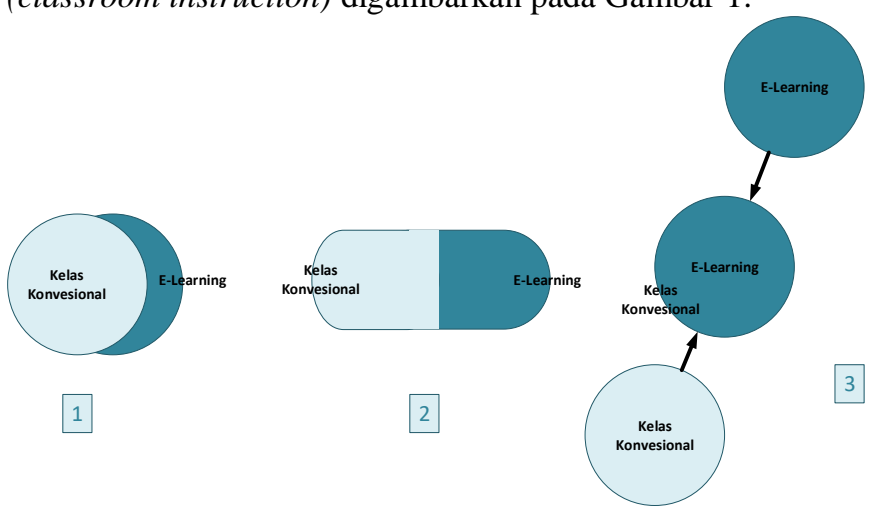

Gambar. 1 Fungsi e-learning terhadap pembelajaran di dalam kelas

Berdasarkan gambar di atas, fungsi e-learning terhadap pembelajaran di dalam kelas dijabarkan sebagai berikut:

\section{Suplemen (tambahan)}

Dikatakan berfungsi sebagai suplemen (tambahan), apabila peserta didik mempunyai kebebasan memilih, apakah akan memanfaatkan materi pembelajaran elektronik atau tidak. Dalam hal ini, tidak ada kewajiban/keharusan bagi peserta didik untuk mengakses materi pembelajaran elektronik. Sekalipun sifatnya 
opsional, peserta didik yang memanfaatkannya tentu akan memiliki tambahan pengetahuan atau wawasan.

\section{Komplemen (pelengkap)}

Dikatakan berfungsi sebagai komplemen (pelengkap) apabila materi pembelajaran elektronik diprogramkan untuk melengkapi materi pembelajaran yang diterima siswa di dalam kelas. Sebagai komplemen berarti materi pembelajaran elektronik diprogramkan untuk menjadi materi reinforcement (pengayaan) atau remedial bagi peserta didik di dalam mengikuti kegiatan pembelajaran konvensional.

\section{Substitusi (pengganti)}

Pengunaan e-learning sebagai pengganti sudah dibuktikan pada perguruan tinggi di beberapa negara maju. Mahasiswa diberikan 3 pilihan yaitu menggunakan pembelajaran konvesional seluruhnya, sebagian menggunakan pembelajaran konvensional dan sebagian lagi menggunakan $e$-learning sedangkan opsi terakhir adalah penggunaan $e$-learning secara sepenuhnya.

\section{Model Komunikasi dalam E-Learning}

Berdasarkan karakteristik komunikasi perangkat lunak dan sumber daya untuk e-learning yang berbeda, maka terdapat tiga kategori dasar di dalam e-learning sebagai berikut:

a. Self-study, artinya peserta dalam proses belajar tidak berinteraksi atau kegiatan belajar tidak terikat waktu. Pendekatan belajar mandiri berorientasi pada alat dan bahan yang disiapkan terlebih dahulu yang digunakan oleh pelajar tanpa interaksi [7]. Contohnya: tutorial, $e$ book / hypermedia, dan latihan.

b. Asynchronous, artinya proses pembelajaran e-learning difasilitasi oleh alat yang tidak mengharuskan peserta hadir pada saat bersamaan [8]. Contohnya: menonton pelajaran video, mengikuti ujian online atau mengajukan pertanyaan ke papan pesan, discussion group, dan lain-lain.

c. Synchronous, artinya proses pembelajaran yang mengharuskan peserta mengikuti virtual bersamaan atau secara live, karena karakteristik real time dari synchronous e-learning [9]. Contohnya: chatting, video conference, dan presenter online.

\section{E. Model Pembelajaran Berbasis E-Learning}

Model pembelajaran berbasis web atau e-learning perlu dirancang secara cermat agar sesuai dengan kebutuhan pengguna dan tujuan yang diharapkan. Adapun beberapa model pembelajaran berbasis web [2] adalah sebagai berikut:

\section{Web-Enhanced Learning}

Model pembelajaran ini menggunakan teknologi internet sebagai sumber belajar tambahan yang bertujuan untuk memperkaya pengetahuan peserta didik yang memperoleh pembelajaran di kelas. Dalam hal ini, pengajar harus menguasai teknik mencari informasi di internet, membimbing peserta didik dalam mencari dan menemukan situs-situs yang sesuai dengan tema pelajaran, menyajikan materi melalui website atau blog, melayani bimbingan dan komunikasi melalui email, dan kecakapan lain yang diperlukan.

\section{Blended/ Hybrid Learning}

Model pembelajaran ini mengkombinasikan pembelajaran online dan tatap muka. Sebagian materi disampaikan melalui internet dan sebagian lagi melalui tatap muka. Tujuannya adalah agar keterbatasan yang terdapat pada pembelajaran tatap muka dapat diatasi dengan pembelajaran melalui e-learning dan kesulitan pelajar dalam belajar melalui e-learning dapat diatasi melalui pembelajaran tatap muka. Dalam model ini, pengajar bisa memberikan petunjuk pada pelajar untuk mempelajari materi pelajaran melalui website yang telah dibuatnya. Pelajar juga diberikan arahan untuk mencari sumber lain dari situs-situs yang relevan. Dalam tatap muka, pelajar dan pengajar lebih banyak diskusi tentang temuan materi yang telah dipelajari melalui website $e$ learning.

\section{Fully Online}

Model pembelajaran ini sebagian besar atau seluruhnya dilaksanakan secara online melalui website elearning. Pengajar dan pelajar sepenuhnya terpisah dan tidak diperlukan adanya tatap muka. Model pembelajaran ini disebut juga dengan distance learning (pembelajaran jarak jauh). Seluruh bahan ajar, diskusi, penugasan, latihan, ujian, dan kegiatan pembelajaran lainnya sepenuhnya disampaikan melalui website e-learning.

Berdasarkan kebijakan pendidikan jarak jauh dan $e-$ learning di Indonesia terdapat proporsi pembelajaran $e$ learning [10] yang dijelaskan pada Tabel 1 .

TABEL I

PROPORSI PEMBELAJARAN E-LEARNING

\begin{tabular}{|c|c|c|}
\hline $\begin{array}{l}\text { Proporsi } \\
\text { Online }\end{array}$ & Deskripsi & Tipe \\
\hline $0 \%$ & $\begin{array}{l}\text { Tatap muka sepenuhnya, } \\
\text { pembelajaran dengan bahan ajar } \\
\text { cetak atau lisan. }\end{array}$ & $\begin{array}{l}\text { Tatap muka } \\
\text { tradisional }\end{array}$ \\
\hline $1 \%-29 \%$ & $\begin{array}{l}\text { Menggunakan teknologi internet } \\
\text { untuk memfasilitasi pola tatap } \\
\text { muka, mungkin menggunakan } \\
\text { LMS atau situs web untuk } \\
\text { mem-pos-kan bahan ajar dan } \\
\text { tugas. }\end{array}$ & $\begin{array}{l}\text { Web- } \\
\text { Enhanced } \\
\text { (pembelajar } \\
\text { an } \\
\text { diperkaya } \\
\text { dengan } \\
\text { akses } \\
\text { internet) }\end{array}$ \\
\hline $30 \%-79 \%$ & $\begin{array}{l}\text { Mengkombinasi cara online dan } \\
\text { tatap muka. Ada proporsi } \\
\text { pengantaran bahan ajar yang } \\
\text { online, biasanya dilengkapi } \\
\text { dengan diskusi online, dan ada } \\
\text { pengurangan frekuensi tatap } \\
\text { muka. }\end{array}$ & $\begin{array}{l}\text { Blended/ } \\
\text { Hybrid } \\
\text { (e-learning) }\end{array}$ \\
\hline$>80 \%$ & $\begin{array}{l}\text { Sebagian besar atau seluruh } \\
\text { bahan ajar diantarkan secara } \\
\text { online, bias tanpa porsi tatap }\end{array}$ & $\begin{array}{l}\text { Fully } \\
\text { Online } \\
\text { (e-learning) }\end{array}$ \\
\hline
\end{tabular}




\begin{tabular}{|c|c|c|}
\hline $\begin{array}{c}\text { Proporsi } \\
\text { Online }\end{array}$ & Deskripsi & Tipe \\
\hline & muka sama sekali. & \\
\hline
\end{tabular}

Model pembelajaran yang digunakan dalam penelitian ini adalah Web-Enhanced Learning. Hal ini dikarenakan proses pembelajaran Web Enhanced melalui internet lebih sedikit dibandingkan dengan pembelajaran tatap muka, karena penggunaan internet hanya untuk pendukung dalam peningkatan kualitas pembelajaran secara tatap muka. Sedangkan kegiatan utama pembelajaran adalah tatap muka di kelas. Oleh karena itu, media pembelajaran sebagai penyedia sumber belajar yang dapat diakses secara online yang dilengkapi dengan fitur-fitur untuk proses pembelajaran yang mendukung Learning Management System (LMS) pada jenjang Madrasah Aliyah.

\section{F. Model Pembelajaran Berbasis E-Learning}

Tahap pengembangan dan pelaksanaan e-learning dilakukan dalam tiga tahapan utama yaitu perancangan (design), pengembangan (development), dan implementasi (deployment) [11] yang dapat dilihat pada Gambar. 2.

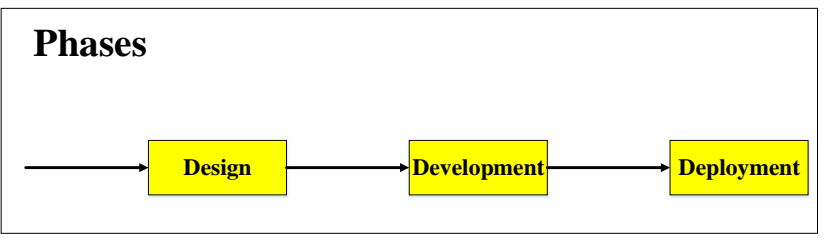

Gambar. 2 Tahap pengembangan dan pelaksanaan e-learning

Berdasarkan Gambar 2, tahapan pengembangan dan pelaksanaan e-learning adalah sebagai berikut:

1. Tahap perancangan (design), dalam tahap ini dilakukan perancangan instruksional yang meliputi analisis tingkat kesulitan, dan pemetaan program (programme mapping).

2. Tahap pengembangan (development), dalam tahap ini terdapat dua tahapan utama yakni tahap pengembangan off-line, dan tahap pengembangan online. Pada tahap pengembangan ini terdapat tiga komponen utama yang harus dikembangkan dalam pembelajaran e-learning yaitu konten, interaksi, dan assessment.

3. Tahap implementasi (deployment), dalam tahap ini terdapat beberapa proses implementasi yakni mulai dari implementasi penggunaan aplikasi LMS, implementasi evaluasi pembelajaran, dan implementasi media komunikasi / interaksi.

\section{G. Learning Management System}

LMS atau Learning Management System adalah sebuah perangkat lunak atau software untuk keperluan administrasi, dokumentasi, pencarian materi, laporan sebuah kegiatan, pemberian materi-materi pelatihan kegiatan belajar mengajar secara online yang terhubung ke internet. LMS menyediakan berbagai tools yang menyediakan layanan untuk mempermudah upload dan share material pengajaran, diskusi online, chatting, penyelenggaraan kuis, survei, laporan (report), dan sebagainya [6]. Salah satu aplikasi Learning Management System (LMS) yang tersedia saat ini yaitu Moodle. Moodle merupakan singkatan dari Modular Object Oriented Dynamic Learning Environment yang berarti tempat belajar dinamis dengan menggunakan model berorientasi objek [12]. Terdapat 14 jenis aktivitas dalam LMS Moodle standar yang tersedia terdiri dari assignments, chat, choice, database, feedback, forum, glossary, lesson, LTI external tool, quiz, SCORM, survey, wiki, dan workshop [13].

Aplikasi yang akan dibangun merupakan bagian dari Learning Management System berbasis Web Enhanced Learning. Perbandingan aplikasi LMS Moodle dengan aplikasi yang akan dibangun ditunjukkan dalam Tabel 2 .

TABEL II

PERBANDINGAN APLIKASI

\begin{tabular}{|c|l|c|c|}
\hline No. & \multicolumn{1}{|c|}{ Perbandingan } & Moodle & $\begin{array}{c}\text { Aplikasi LMS } \\
\text { Pada Jenjang } \\
\text { MA }\end{array}$ \\
\hline 1. & $\begin{array}{l}\text { Pengguna memiliki akun } \\
\text { berdasarkan hak akses } \\
\text { (pengajar dan siswa) }\end{array}$ & $\sqrt{ }$ & $\sqrt{ }$ \\
\hline 2. & $\begin{array}{l}\text { Materi pembelajaran yang } \\
\text { terkategorisasi }\end{array}$ & $\sqrt{ }$ & $\sqrt{ }$ \\
\hline 4. & $\begin{array}{l}\text { Tersedia fitur } \\
\text { pembelajaran } \\
\text { asynchronous }\end{array}$ & $\sqrt{ }$ & $\sqrt{ }$ \\
\hline 5. & $\begin{array}{l}\text { Tersedia fitur } \\
\text { pembelajaran synchronous }\end{array}$ & $\sqrt{ }$ & $\times$ \\
\hline 6. & $\begin{array}{l}\text { Menulis di blog } e- \\
\text { learning }\end{array}$ & $\sqrt{ }$ & $\times$ \\
\hline 7. & Aplikasi mobile & $\sqrt{ }$ & $\times$ \\
\hline
\end{tabular}

Pada aplikasi LMS yang akan dibangun dalam penelitian ini menyediakan fitur dengan aktivitas $e$ learning utama meliputi aktivitas pembelajaran (modul, link terkait, diskusi, tugas), dan aktivitas evaluasi (tugas dan tes). Fitur-fitur yang disediakan ini lebih spesifik dan disesuaikan berdasarkan Rencana Pelaksanaan Pembelajaran (RPP) MAN 1 Kubu Raya. Sehingga dalam penggunaan LMS pada jenjang Madrasah Aliyah ini sesuai dengan kebutuhan yang diperlukan sejalan dengan pokok bahasan dan kompetensi yang harus dicapai pada mata pelajaran yang dijelaskan dalam Rencana Pelaksanaan Pembelajaran (RPP).

\section{H. Standar Kompetensi Lulusan pada Jenjang Pendidikan Menengah}

Standar Kompetensi Lulusan adalah kriteria mengenai kualifikasi kemampuan lulusan yang mencakup sikap, pengetahuan, dan keterampil. Standar Kompetensi Lulusan digunakan sebagai acuan utama pengembangan standar isi, standar proses, standar penilaian pendidikan, standar pendidik dan tenaga kependidikan, standar sarana dan prasarana, standar pengelolaan, dan standar 
pembiayaan. Standar Kompetensi Lulusan terdiri atas kriteria kualifikasi kemampuan peserta didik yang diharapkan dapat dicapai setelah menyelesaikan masa belajarnya di satuan pendidikan pada jenjang pendidikan dasar dan menengah [14].

\section{Silabus dan Rencana Pelaksanaan Pembelajaran (RPP)}

Perangkat pembelajaran yang digunakan untuk mencapai Standar Kompetensi Lulusan adalah kurikulum 2013, silabus, dan Rencana Pelaksanaan Pembelajaran (RPP). Kurikulum 2013 adalah kurikulum yang terintegrasi, maksudnya adalah suatu model kurikulum yang dapat mengintegrasikan skill, themes, concepts, and topics baik dalam bentuk within single disciplines, across several disciplines and within and across learners [15]. Rencana Pelaksanaan Pembelajaran (RPP) adalah rencana pembelajaran yang pengembangannya megacu pada suatu KD tertentu di dalam kurikulum atau silabus. Selain RPP dikenal pula istilah silabus, yakni pedoman rencana pembelajaran yang fungsinya sebagai acuan pengembangan RPP. Di dalamnya memuat identitas mata pelajaran atau tema pelajaran, kompetensi isi (KI), kompetensi dasar (KD), materi pelajaran, kegiatan pembelajaran, indikator pencapaian kompetensi, penilaian, alokasi waktu, dan sumber belajar. Silabus dikembangkan oleh satuan pendidikan berdasarkan KI dan KD dalam kurikulum. Sedangkan untuk kurikulum 2013, silabus disusun oleh pemerintah di tingkat nasional [16].

\section{J. Metode Pengembangan Sistem}

Metode pengembangan sistem yang sering digunakan dalam tahapan pengembangan sistem yaitu model SDLC air terjun (waterfall) adalah "Model sekuensial linier (sequential linear) atau alur hidup klasik (classic life cycle). Model air terjun menyediakan pendekatan alur hidup perangkat lunak secara sekuential atau terurut dimulai dari analisis, desain, pengkodean, pengujian dan tahap pendukung (support)" [17]. Gambar model air terjun (waterfall) dapat dilihat pada Gambar 3.

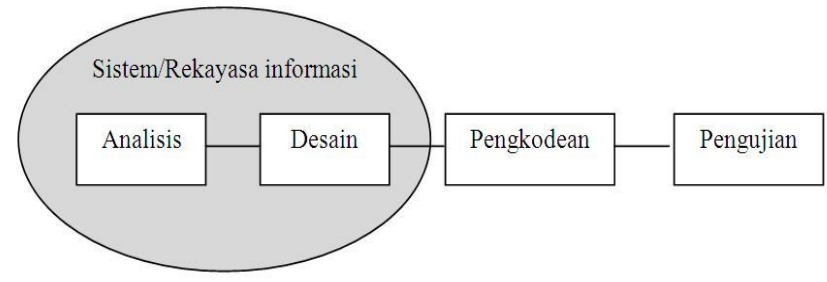

Gambar. 3 Model Waterfall

\section{K. Pengujian Sistem}

Pengujian yang dilakukan dalam penelitian ini sebagai tahap implementasi untuk mengetahui tingkat keberhasilan sistem yang dikembangkan sesuai dengan tujuan dari penelitian. Pengujian dapat diartikan sebagai suatu proses yang dilakukan untuk menilai apakah yang dirancang telah sesuai dengan apa yang diharapkan, yakni melakukan penilaian dan evaluasi terhadap komponen sistem prosedur kegiatan dan kualitas hasil sistem [18]. Adapun pengujian yang akan digunakan dalam penelitian ini yaitu pengujian User Acceptance Test (UAT) dan Pre test - Post test.

\section{User Acceptance Test (UAT)}

User Acceptance Test adalah suatu proses pengujian yang dilakukan oleh pengguna dengan hasil output sebuah dokumen hasil uji yang dapat dijadikan bukti bahwa software sudah diterima dan sudah memenuhi kebutuhan yang diminta [19]. Teknik pengujian UAT yang digunakan dalam penelitian ini yaitu menggunakan metode kuesioner. Kuesioner berisi tentang daftar pertanyaan yang akan ditujukan kepada para responden yang bersedia memberikan respon sesuai dengan permintaan pemberi pertanyaan [20]. Adapun responden dalam penelitian ini adalah ahli materi, pengajar, dan siswa. Tujuan dari pengujian ini untuk mengetahui kelayakan media pembelajaran yang telah dikembangkan. Hasil penilaian terhadap seluruh aspek di ukur dengan skala likert. Skala likert merupakan sejumlah pernyataan positif atau negatif mengenai suatu obyek sikap. Sedangkan untuk menghitung analisis hasil kuesioner menggunakan rumus perhitungan rating scale [21] sebagai berikut:

$$
\text { Persentase }(\%)=\frac{\sum \text { Skoryang diperoleh }}{\text { Skor ideal }} x 100 \%
$$

Persentase yang telah diperoleh kemudian ditransformasikan ke dalam tabel untuk menentukan kriteria kualitatif yakni mengetahui kelayakan media yang telah dikembangkan [22] yang dapat dilihat pada Tabel 3.

TABEL III

KRITERIA KELAYAKAN MEDIA

\begin{tabular}{|l|l|l|}
\hline No & \multicolumn{1}{|c|}{ Skor dalam Persen (\%) } & \multicolumn{1}{|c|}{$\begin{array}{c}\text { Kategori } \\
\text { Kelayakan }\end{array}$} \\
\hline 1 & $<21 \%$ & Sangat Tidak layak \\
\hline 2 & $21-40 \%$ & Tidak Layak \\
\hline 3 & $41-60 \%$ & Cukup Layak \\
\hline 4 & $61-80 \%$ & Layak \\
\hline 5 & $81-100 \%$ & Sangat Layak \\
\hline
\end{tabular}

Kriteria penilaian kelayakan media pembelajaran yaitu terdiri dari subject matter, auxiliary information, affective consideration, interface, navigation, pedagogy, invisible features, robustness, dan supplementary materials [23]. Adapun tiga aspek penilaian pada media pembelajaran yang dapat digunakan yakni aspek rekayasa perangkat lunak (pemrograman), aspek instructional design (desain pembelajaran), dan aspek komunikasi visual [24]

Dalam penelitian ini aspek penilaian media pembelajaran menggunakan tiga aspek penilaian yaitu aspek pemrograman, aspek pembelajaran, dan aspek pedagogi. Adapun indikator penilaian yang digunakan 
pada aspek pemrograman terdiri dari kompatibilitas, usabilitas, maintainable, interface (tampilan), bahasa, dan robustness. Indikator penilaian pada aspek pembelajaran terdiri dari kesesuaian tujuan, kejelasan uraian, akurasi isi, kedalaman materi, bahasa, struktur isi, konten pembelajaran, dan kesesuaian sumber materi, penjadwalan, kelengkapan dan kualitas bahan ajar, dan kemudahan untuk dipahami. Sedangkan indikator penilaian pada aspek pedagogi terdiri dari kontrol pengguna, interaktif, kualitas umpan balik, pertanyaan, jawaban pertanyaan, penilaian, dan strategi pembelajaran.

\section{Pre Test-Post Test}

Pre test adalah kegiatan menguji tingkatan pengetahuan siswa terhadap materi yang akan disampaikan, kegiatan pre test dilakukan sebelum kegiatan pengajaran diberikan. Sementara post test adalah kegiatan menguji tingkat pengetahuan siswa terhadap materi yang baru selesai disampaikan. Hasil post test ini dibandingkan dengan hasil pre test yang telah dilakukan sehingga akan diketahui seberapa jauh efek atau pengaruh dari pengajaran yang telah dilakukan, disamping itu sekaligus dapat diketahui bagian mana dari bahan pengajaran yang masih belum dipahami oleh sebagian besar siswa. Teknik analisis peningkatan hasil belajar siswa menggunakan skor Normalized Gain (N-Gain). Gain adalah selisih antara nilai post test dan pre test, menunjukkan peningkatan pemahaman atau penguasaan konsep siswa setelah proses pembelajaran [25]. Analisis dilakukan dengan menggunakan rumus gain ternormalisasi rata-rata (average normalized gain) [26] sebagai berikut:

$$
\mathrm{g}=\frac{\text { Skor Past Test - Skor PreTest }}{\text { Skor Maksimum }- \text { Skor Pre Test }}
$$

\section{Keterangan:}

$\mathrm{g}=$ nilai gain ternormalisasi

Berdasarkan skor gain yang diperoleh, nilai hasil belajar siswa dikelompokkan menurut kriteria skor $\mathrm{N}$-Gain seperti pada Tabel 4.

TABEL IV

INTERPRETASI NORMALIZED GAIN

\begin{tabular}{|l|l|}
\hline \multicolumn{1}{|c|}{$\begin{array}{c}\text { Nilai } \text { (Normalized Gain } \\
\text { Score) }\end{array}$} & \multicolumn{1}{|c|}{$\begin{array}{c}\text { Interpretasi } \\
\text { (Interpretation) }\end{array}$} \\
\hline $\mathrm{g}>0.7$ & Tinggi(High) \\
\hline $0.3 \leq \mathrm{g} \leq 0.7$ & Sedang (Medium) \\
\hline $0<\mathrm{g}<0.3$ & Rendah $($ Low $)$ \\
\hline
\end{tabular}

\section{Metodologi Penelitian DAN PeRAnCANGAN SiStem}

\section{A. Metodologi Penelitian}

Metodologi penelitian ini bertujuan untuk menggambarkan tahapan penelitian yang dilakukan, yakni memiliki beberapa tahapan yang dapat dilihat pada Gambar 4.

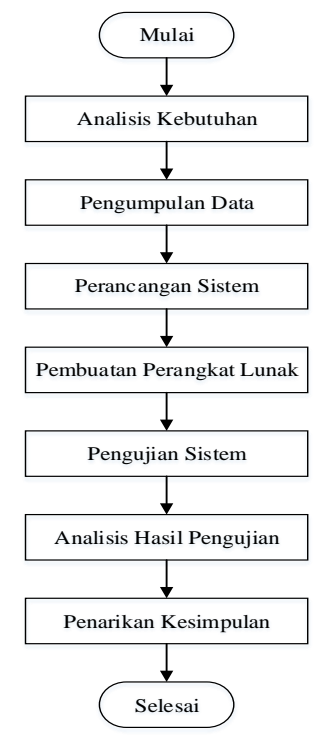

Gambar. 4 Metodologi penelitian

\section{B. Perancangan Arsitektur Sistem}

Arsitektur sistem adalah gambaran umum perancangan sistem yang akan dibangun. Aplikasi LMS ini dibangun berbasis web, data informasi terkait pembelajaran akan disimpan ke dalam database sistem yang akan dikelola oleh administrator dan kemudian menghasilkan informasi yang nantinya dapat diakses oleh pengajar dan siswa. Pengajar juga dapat mengelola data pembelajaran di web ini. Perancangan arsitektur sistem tersebut dapat dilihat pada Gambar 5.

(2)

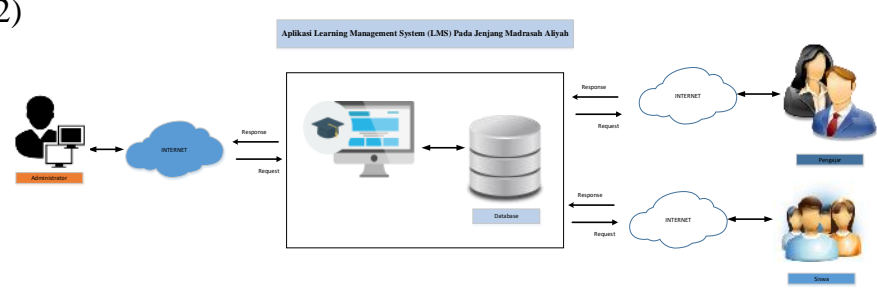

Gambar. 5 Arsitektur sistem

\section{Tahap Perancangan (Design) Instruksional}

Pada tahap ini dilakukan rancangan instruksional pada mata pelajaran Bahasa Inggris kelas XII MAN 1 Kubu Raya dengan materi pokok teks procedure. Pada rancangan instruksional ini didasarkan pada Rencana Pelaksanaan Pembelajaran (RPP) yang sudah dimiliki oleh pengajar MAN 1 Kubu Raya. Dalam rancangan instruksional akan dilakukan dua tahapan utama yaitu analisis tingkat kesulitan (difficulty analysis), dan pemetaan program atau programme mapping (RPP).

\section{Analisis Tingkat Kesulitan (Difficulty Analysis)}

Menjelaskan diagram alir capaian pembelajaran hingga kompetensi. Pada analisis tingkat kesulitan 
dipaparkan dalam struktur rancangan yang meliputi pokok bahasan, sub-pokok bahasan, Kompetensi Dasar (KD), indikator, Kriteria Ketuntasan Minimal (KKM), alokasi waktu, dan tingkat kesulitan.

\section{Pemetaan Program (Programme Mapping)}

Menjelaskan kompetensi dasar dan pembuatan programme mapping atau Rencana Pelaksanaan Pembelajaran (RPP) untuk proses pembelajaran. Programme mapping merupakan tindak lanjut dari hasil analisis tingkat kesulitan. Pada programme mapping dipaparkan dalam struktur rancangan yang meliputi pokok bahasan, sub-pokok bahasan, Kompetensi Dasar (KD), indikator, tingkat kesulitan, metode pembelajaran (learning method), metode penyampaian (delivery method), dan assessment method (metode penilaian).

Hasil rancangan program e-learning dituangkan dalam rancangan aktivitas e-learning. Dalam penelitian ini, rancangan aktivitas e-learning dibuat berdasarkan RPP (Rencana Pelaksanaan Pembelajaran). Rancangan ini untuk mengetahui aktivitas e-learning yang diperlukan sesuai dengan pokok bahasan dan kompetensi yang harus dicapai pada mata pelajaran yang dijelaskan dalam Rencana Pelaksanaan Pembelajaran (RPP). Aktivitas $e$ learning yang didukung oleh aplikasi LMS pada jenjang Madrasah Aliyah ini dibagi dalam dua aktivitas utama yaitu:

\section{Aktivitas Pembelajaran}

Aktivitas pembelajaran terdiri dari:

a. Modul, dalam hal ini adalah konten materi pelajaran yang dikembangkan sendiri atau konten dari luar yang akan digunakan.

b. Link, yaitu konten luar yang disarankan kepada siswa untuk dipelajari.

c. Diskusi yang berbentuk komentar pada materi dan chat.

d. Tugas, dalam hal ini adalah penyampaian pembelajaran dalam bentuk penugasan yaitu tugas terstruktur baik individu dan kelompok.

\section{Aktivitas Evaluasi}

Aktivitas evaluasi terdiri dari:

a. Tugas yaitu evaluasi melalui format penugasan secara individu dan kelompok.

b. Tes yaitu evaluasi melalui ujian/kuis secara online berupa pilihan ganda dan essay.

\section{Tahap Pengembangan (Development)}

Pada tahap pengembangan (development) e-learning ini dibagi menjadi dua tahapan utama yaitu:

\section{Tahap Pengembangan (Development) - Off-Line}

Terdapat tiga komponen utama yang harus dikembangkan dalam pembelajaran menggunakan sistem online, yaitu:

a. Konten, terdapat tiga pengembangan yang dilakukan yaitu sebagai berikut:
1. Pengembangan handout, yaitu konten materi yang dibuat dapat berbentuk file berupa .doc, .zip, .rar, .txt, .docx, .xls, .xlsx, .pdf, .t ar, .gz, .jpg, .jpeg, .JPG, .JPEG, .png, .ppt, .pptx.

2. Pengembangan gambar atau animasi, yaitu konten materi dengan penggunaan gambar yang dapat disatukan ke dalam handout, sedangkan animasi dapat berdiri sendiri sebagai satu bahan ajar atau dihubungkan/di-link dalam handout. Gambar atau animasi dapat dibuat sendiri atau diambil dari sumber lain seperti buku atau internet dengan mencantumkan sumbernya langsung dalam gambar atau animasi tersebut.

3. Pengembangan video lecture, yaitu penjelasan materi pelajaran dapat juga dibuat dalam bentuk audio video, seperti video slide powerpoint disertai narasi (dosen atau pengisi suara) atau video pembelajaran lainnya.

b. Interaksi, yaitu terdapat fitur activity yang berfungsi sebagai fasilitas interaksi antara pengajar dengan siswa atau sesama siswa dengan menggunakan chat atau melalui kolom komentar materi.

c. Assessment, yaitu terdapat fitur activity yang berfungsi untuk evaluasi pembelajaran siswa berupa tugas terstruktur dan kuis atau ujian online pilihan ganda atau essay.

\section{E. Tahap Implementasi (Development)}

Pada tahap implementasi (deployment) terdapat tiga tahapan utama yang dilakukan yaitu tahap implementasi penggunaan aplikasi LMS, tahap implementasi terkait evaluasi pembelajaran, dan tahap implementasi terkait media komunikasi / interaksi.

\section{F. Perancangan Antarmuka Sistem}

Pada perancangan antarmuka sistem terdapat tiga user atau pengguna yaitu administrator, pengajar, dan siswa. Struktur antarmuka sistem dapat dilihat pada Gambar 6.

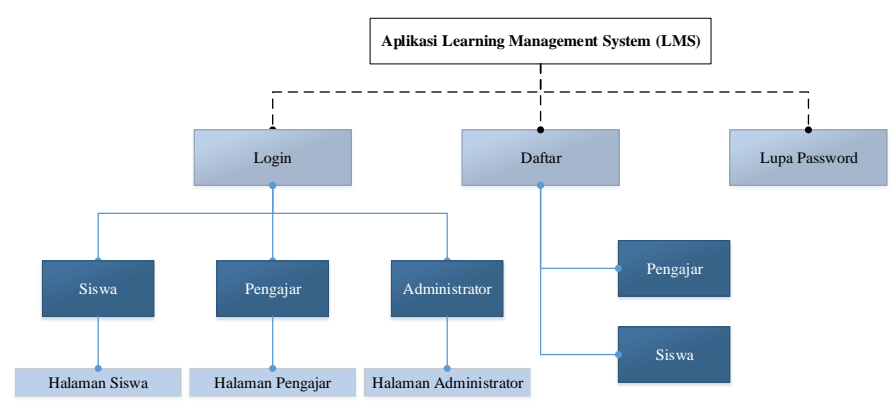

Gambar. 6 Struktur antarmuka sistem

Sedangkan untuk penjabaran struktur antarmuka sistem terkait dengan penggunaan Aplikasi Learning Management System Pada Jenjang Madrasah Aliyah dapat dilihat pada Gambar 7. 


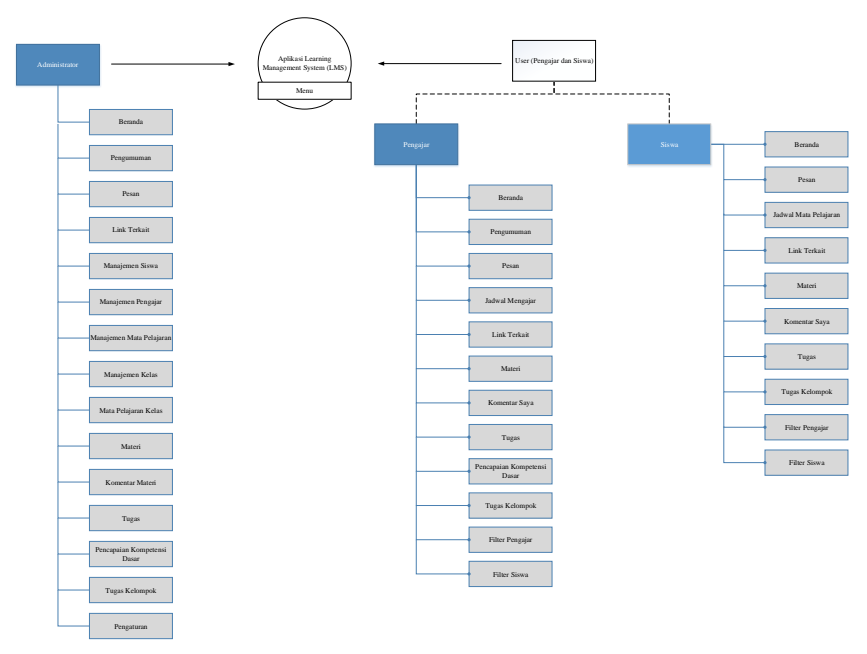

Gambar. 7 Penjabaran struktur antarmuka sistem

\section{HASIL DAN PEMBAHASAN}

\section{A. Implementasi}

Aplikasi yang dirancang merupakan sebuah aplikasi Learning Management System yang digunakan sebagai media pendukung dalam pembelajaran. Pada aplikasi yang dirancang terdapat beberapa fitur yang dilengkapi dengan materi atau bahan ajar, kuis online, tugas kelompok, menu upload tugas, menu bank soal, menu penilaian, menu analisis soal, menu analisis pencapaian kompetensi dasar, link ke website lain, pengumuman, komentar, dan chat. Aplikasi ini memiliki beberapa bagian berdasarkan hak akses user yaitu administrator, pengajar, dan siswa. Halaman utama yang dapat dilihat pada Gambar 8, yaitu menampilkan tampilan utama dari aplikasi yang diakses oleh user. Halaman administrator yang dapat dilihat pada Gambar 9, yaitu halaman yang hanya dapat di akses oleh administrator untuk mengelola data secara keseluruhan. Halaman pengajar yang dapat dilihat pada Gambar 10, yaitu halaman yang hanya dapat diakses oleh pengajar untuk mengelola data pembelajaran. Halaman siswa yang dapat dilihat pada Gambar 11, yaitu halaman yang hanya dapat diakses oleh siswa untuk mengakses data pembelajaran sesuai dengan kelas yang diikuti oleh siswa.

\section{B. Hasil Pengujian}

Pengujian sistem menggunakan strategi pembanding pengujian yaitu User Acceptance Test (UAT) dan pre test - post test. Hal ini dilakukan untuk mengetahui apakah sistem sudah sesuai dengan tujuan yang diharapkan.

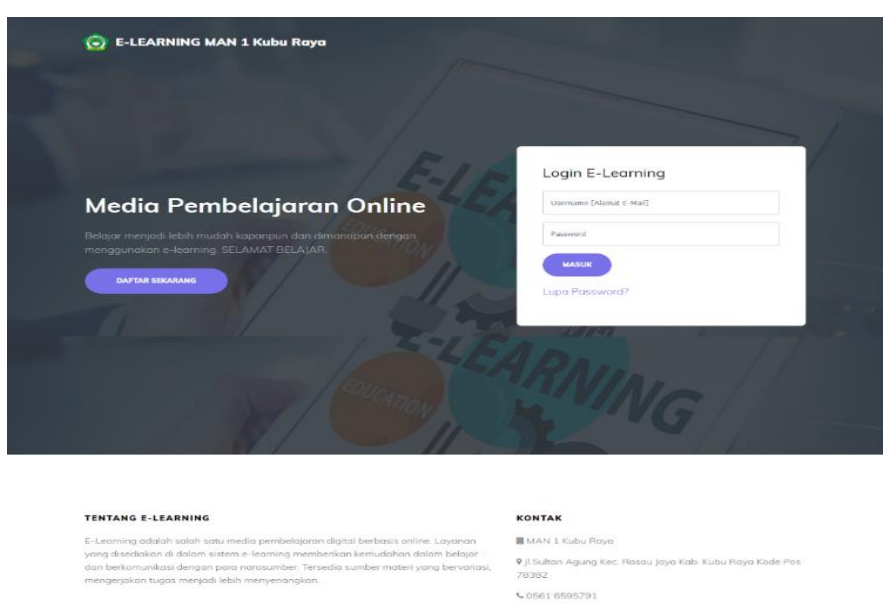

Gambar. 8 Antarmuka halaman utama

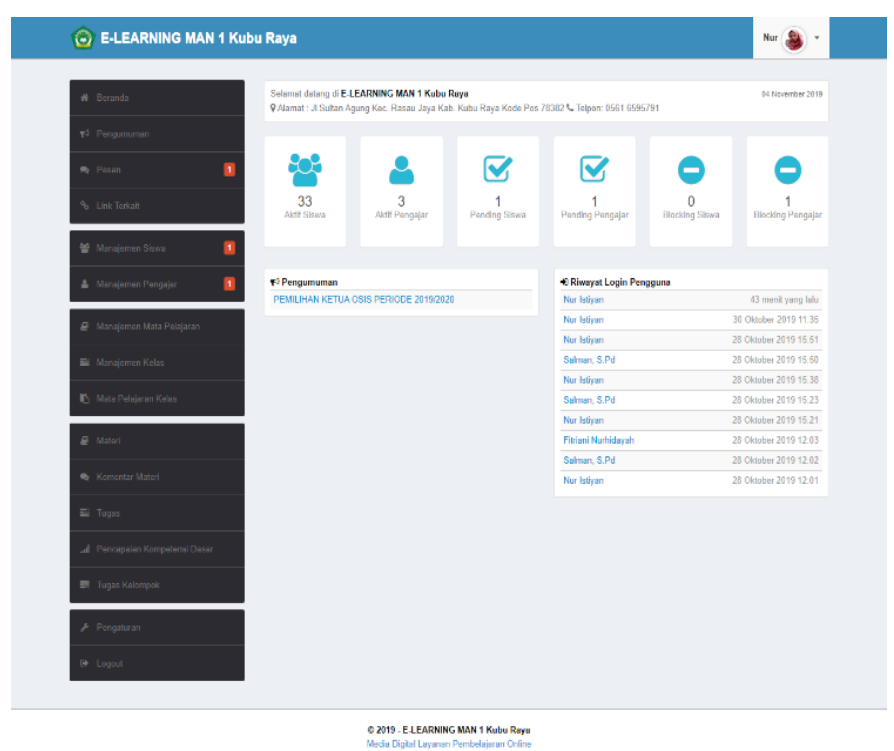

Gambar. 9 Antarmuka halaman administrator

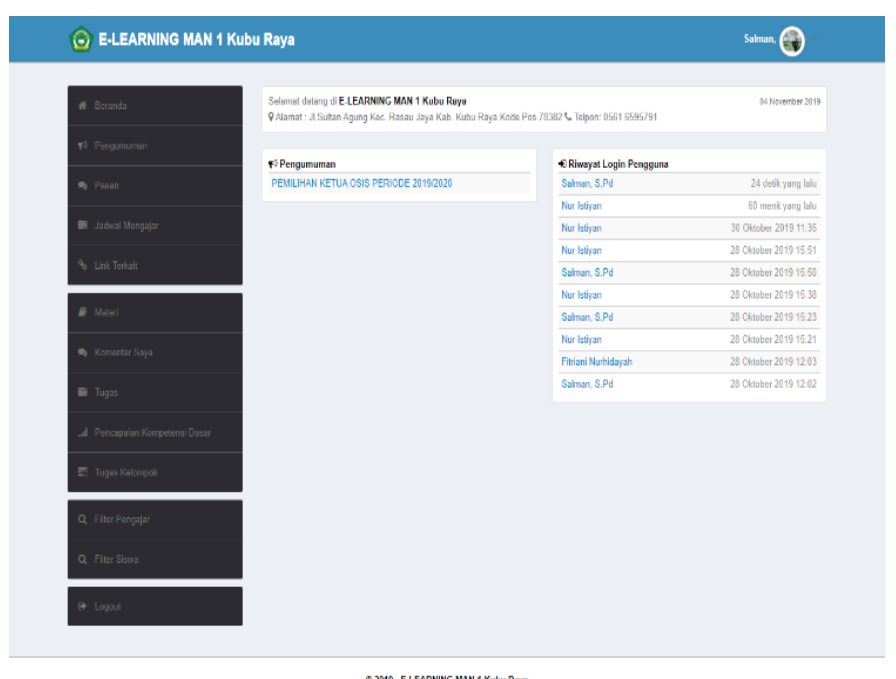

O2019. ELEARNAMG MaN 1 Kulu Rerr

Gambar. 10 Antarmuka halaman pengajar 


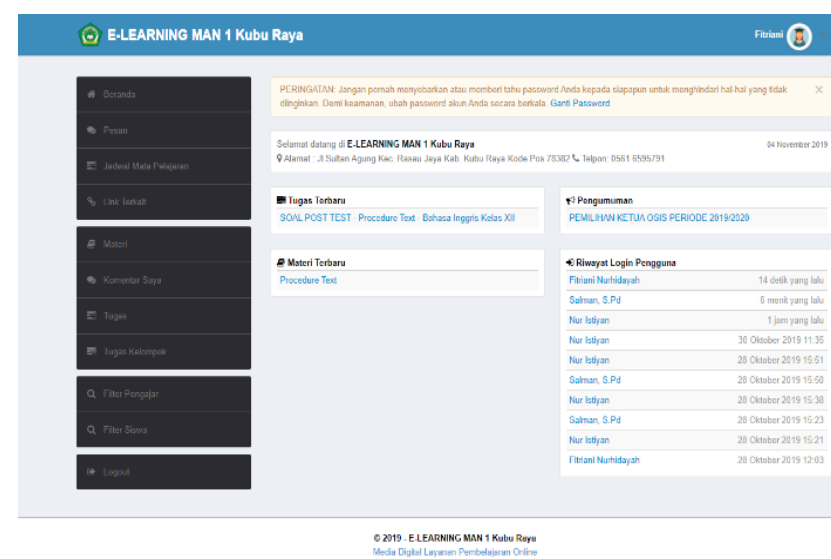

Gambar. 11 Antarmuka halaman siswa

\section{Pengujian User Acceptance Test (UAT)}

Metode yang digunakan dalam pengujian ini adalah menggunakan metode kuesioner. Instrumen yang digunakan ditujukan untuk menilai kelayakan media pembelajaran yang telah dikembangkan. Data yang diperoleh dari kuesioner ini adalah data kuantitatif dari responden yaitu satu orang ahli materi, dua orang pengajar, dan 23 orang siswa. Hasil kuesioner oleh responden berupa hasil tanggapan dan penilaian, kemudian dari hasil data yang diperoleh dihitung dan dianalisis untuk mengetahui kelayakan media pembelajaran yang telah dikembangkan. Berikut hasil data kuesioner dari responden.

\section{a. Hasil Kuesioner oleh Ahli Materi}

Hasil skor diperoleh berdasarkan dua aspek penilaian yaitu aspek pembelajaran, dan aspek pedagogi. Hasil penilaian ahli materi dapat dilihat pada Tabel 5.

TABEL V

Hasil Penilaian Oleh Ahli Materi

\begin{tabular}{|c|c|c|c|c|}
\hline $\begin{array}{l}\mathbf{N} \\
\mathbf{o}\end{array}$ & $\begin{array}{c}\text { Aspek } \\
\text { Penilaian }\end{array}$ & Indikator & $\begin{array}{c}\text { Jumlah } \\
\text { Butir } \\
\text { Soal }\end{array}$ & $\begin{array}{l}\text { Total } \\
\text { Hasil } \\
\text { Skor } \\
\left(\sum x\right)\end{array}$ \\
\hline \multirow[t]{6}{*}{1.} & \multirow{6}{*}{$\begin{array}{l}\text { Aspek } \\
\text { Pembelajaran }\end{array}$} & Kesesuaian tujuan & 2 & 9 \\
\hline & & Kejelasan uraian & 1 & 5 \\
\hline & & Akurasi isi & 1 & 5 \\
\hline & & Kedalaman materi & 1 & 5 \\
\hline & & Bahasa & 1 & 5 \\
\hline & & Struktur isi & 1 & 5 \\
\hline \multirow[t]{4}{*}{2.} & \multirow{4}{*}{$\begin{array}{l}\text { Aspek } \\
\text { Pedagogi }\end{array}$} & Pertanyaan & 2 & 8 \\
\hline & & $\begin{array}{l}\text { Strategi } \\
\text { pembelajaran }\end{array}$ & 2 & 10 \\
\hline & & $\begin{array}{l}\text { Kualitas umpan } \\
\text { balik }\end{array}$ & 2 & 8 \\
\hline & & Jawaban pertanyaan & 1 & 4 \\
\hline \multicolumn{4}{|c|}{ Total Keseluruhan } & 64 \\
\hline \multicolumn{4}{|c|}{ Persentase $(\%)$} & 91.42 \\
\hline
\end{tabular}

Berdasarkan tabel di atas menunjukkan bahwa hasil skor ditinjau dari aspek pembelajaran, dan aspek pedagogi memperoleh nilai total rata-rata dari keseluruhan aspek adalah $91.42 \%$, sehingga dapat disimpulkan aplikasi
Learning Management System pada jenjang Madrasah Aliyah dikategorikan "Sangat Layak" untuk digunakan.

b. Hasil Kuesioner oleh Pengajar

Hasil skor diperoleh berdasarkan tiga aspek penilaian yaitu aspek pembelajaran, aspek pemrograman, dan aspek pedagogi. Hasil penilaian pengajar dapat dilihat pada Tabel 6.

TABEL VI

Hasil PENILAian Oleh PENGaJaR

\begin{tabular}{|c|c|c|c|c|}
\hline No & $\begin{array}{c}\text { Aspek } \\
\text { Penilaian }\end{array}$ & Indikator & $\begin{array}{c}\text { Jumlah } \\
\text { Butir } \\
\text { Soal }\end{array}$ & $\begin{array}{c}\text { Total } \\
\text { Hasil } \\
\text { Skor } \\
\left(\sum x\right)\end{array}$ \\
\hline \multirow[t]{4}{*}{1.} & \multirow[t]{4}{*}{$\begin{array}{l}\text { Aspek } \\
\text { Pembelajaran }\end{array}$} & $\begin{array}{l}\text { Konten } \\
\text { pembelajaran }\end{array}$ & 1 & 9 \\
\hline & & $\begin{array}{l}\text { Kesesuaian sumber } \\
\text { materi }\end{array}$ & 2 & 16 \\
\hline & & Bahasa & 1 & 9 \\
\hline & & Penjadwalan & 1 & 9 \\
\hline \multirow[t]{4}{*}{2.} & \multirow{4}{*}{$\begin{array}{l}\text { Aspek } \\
\text { Pemrograman }\end{array}$} & Kompatibilitas & 1 & 9 \\
\hline & & Usabilitas & 6 & 50 \\
\hline & & Maintainable & 6 & 52 \\
\hline & & Tampilan & 2 & 18 \\
\hline \multirow[t]{6}{*}{3.} & \multirow{6}{*}{$\begin{array}{l}\text { Aspek } \\
\text { Pedagogi }\end{array}$} & Kontrol pengguna & 2 & 16 \\
\hline & & Interaktif & 1 & 8 \\
\hline & & $\begin{array}{l}\text { Kualitas umpan } \\
\text { balik }\end{array}$ & 1 & 9 \\
\hline & & $\begin{array}{l}\text { Jawaban } \\
\text { pertanyaan }\end{array}$ & 1 & 9 \\
\hline & & Pertanyaan & 1 & 8 \\
\hline & & Penilaian & 1 & 8 \\
\hline \multicolumn{4}{|c|}{ Total Keseluruhan } & 230 \\
\hline \multicolumn{4}{|c|}{ Persentase (\%) } & 84.95 \\
\hline
\end{tabular}

Berdasarkan tabel di atas menunjukkan bahwa hasil skor ditinjau dari aspek pembelajaran, aspek pemrograman, dan aspek pedagogi memperoleh nilai total rata-rata dari keseluruhan aspek adalah $84.95 \%$, sehingga dapat disimpulkan aplikasi Learning Management System pada jenjang Madrasah Aliyah dikategorikan "Sangat Layak" untuk digunakan.

c. Hasil Kuesioner oleh Siswa

Hasil skor diperoleh berdasarkan tiga aspek penilaian yaitu aspek pembelajaran, aspek pemrograman, dan aspek pedagogi. Hasil penilaian siswa dapat dilihat pada Tabel 7.

TABEL VII

Hasil PENILAIAN OLEH Siswa

\begin{tabular}{|c|l|l|l|l|}
\hline $\begin{array}{c}\text { N } \\
\text { o }\end{array}$ & \multicolumn{1}{|c|}{$\begin{array}{c}\text { Aspek } \\
\text { Penilaian }\end{array}$} & Indikator & $\begin{array}{c}\text { Jumlah } \\
\text { Butir } \\
\text { Soal }\end{array}$ & $\begin{array}{c}\text { Total Hasil } \\
\text { Skor }(\Sigma \mathbf{x})\end{array}$ \\
\hline \multirow{2}{*}{1.} & $\begin{array}{l}\text { Aspek } \\
\text { Pemrograman }\end{array}$ & Usabilitas & 4 & 390 \\
\cline { 3 - 5 } & Tampilan & 2 & 215 \\
\cline { 3 - 5 } & Bahasa & 1 & 108 \\
\cline { 3 - 5 } & Robustness & 1 & 89 \\
\hline 2. & $\begin{array}{l}\text { Aspek } \\
\text { Pembelajaran }\end{array}$ & $\begin{array}{l}\text { Kelengkapa } \\
\text { n dan } \\
\text { kualitas } \\
\text { bahan ajar }\end{array}$ & 1 & \\
\hline
\end{tabular}




\begin{tabular}{|c|l|l|l|l|}
\hline $\begin{array}{c}\text { N } \\
\text { o }\end{array}$ & \multicolumn{1}{|c|}{$\begin{array}{c}\text { Aspek } \\
\text { Penilaian }\end{array}$} & Indikator & $\begin{array}{c}\text { Jumlah } \\
\text { Butir } \\
\text { Soal }\end{array}$ & $\begin{array}{c}\text { Total Hasil } \\
\text { Skor }\left(\sum x\right)\end{array}$ \\
\hline \multirow{2}{*}{3.} & $\begin{array}{l}\text { Aspek } \\
\text { Pedagogi }\end{array}$ & $\begin{array}{l}\text { Kemudahan } \\
\text { untuk } \\
\text { dipahami }\end{array}$ & 1 & 84 \\
\cline { 3 - 5 } & $\begin{array}{l}\text { Kertanyaan } \\
\text { umpan } \\
\text { balik }\end{array}$ & 1 & 94 \\
\cline { 3 - 5 } & $\begin{array}{l}\text { Kontrol } \\
\text { Pengguna }\end{array}$ & 2 & 108 \\
\cline { 3 - 5 } & Interaktif & 1 & 176 \\
\hline
\end{tabular}

Berdasarkan tabel di atas menunjukkan bahwa hasil skor ditinjau dari aspek pemrograman, aspek pembelajaran, dan aspek pedagogi memperoleh nilai total rata-rata dari keseluruhan aspek adalah $84.29 \%$, sehingga dapat disimpulkan aplikasi Learning Management System pada jenjang Madrasah Aliyah dikategorikan "Sangat Layak" untuk digunakan.

\section{Pre Test-Post Test}

Pre test - post test dilakukan untuk mengetahui peningkatan hasil belajar siswa. Pre test - post test dilakukan kepada siswa Kelas XII MAN 1 Kubu Raya dengan total siswa sebanyak 54 orang yang terbagi menjadi 2 kelompok yaitu kelompok kelas yang menggunakan aplikasi LMS (XII MIPA-2) sebanyak 23 orang dan kelompok kelas yang menggunakan buku teks (XII MIPA-1) sebanyak 31 orang. Hasil pre test dan post test dapat dilihat pada rangkuman hasil nilai pre test post test pada Tabel 8.

TABEL VIII

RANGKuman Hasil NILAI PRE TEST-POST TEST

\begin{tabular}{|c|c|c|c|c|c|c|c|c|c|}
\hline Kel & \multirow{2}{*}{ N } & \multicolumn{4}{|c|}{ Pre Test } & \multicolumn{4}{c|}{ Post Test } \\
\cline { 3 - 10 } & & $\boldsymbol{M}$ & $\boldsymbol{M}$ & $\boldsymbol{M E}$ & $\boldsymbol{M}$ & $\boldsymbol{M}$ & $\boldsymbol{M A}$ & $\boldsymbol{M}$ & $\boldsymbol{M}$ \\
& & $\boldsymbol{I N}$ & $\boldsymbol{A}$ & $\boldsymbol{A N}$ & $\boldsymbol{O}$ & $\boldsymbol{I N}$ & $\boldsymbol{X}$ & $\boldsymbol{E}$ & $\boldsymbol{O}$ \\
& & & $\boldsymbol{X}$ & & $\boldsymbol{D}$ & & & $\boldsymbol{A}$ & $\boldsymbol{D}$ \\
& & & & & $\boldsymbol{E}$ & & & $\boldsymbol{N}$ & $\boldsymbol{E}$ \\
\hline $\mathrm{KK}$ & 31 & 13. & 80 & 48.6 & 40 & 40 & 80 & 56. & 46. \\
& & 33 & & 0 & & & & 34 & 67 \\
\hline & & & & & & & & & \\
\hline KE & 23 & 20 & 86. & 55.0 & 53. & 53. & 100 & 77. & 93. \\
& & & 67 & 7 & 33 & 33 & & 54 & 33 \\
\hline
\end{tabular}

Keterangan:

$\mathrm{KK}=$ Kelas Kontrol (XII MIPA-1)

$\mathrm{KE}=$ Kelas Eksperimen (XII MIPA-2)

Pada Tabel 8 menunjukkan bahwa hasil pre test - post test pada kedua kelas yang menggunakan media pembelajaran yang berbeda memiliki perbedaan hasil belajar siswa. Hasil data yang diperoleh selanjutnya dianalisis untuk mengetahui peningkatan hasil belajar siswa menggunakan skor gain (N-Gain) dan kemudian dikelompokkan menurut skala gain. Rekapitulasi hasil perbedaan rerata pre test - post test antara kelompok ( $N$ Gain) terhadap peningkatan hasil belajar siswa dapat dilihat pada Tabel 9.
TABEL IX

REKAPITUlasi HASIL RERATA ANTARA KELOMPOK (N-GAIN)

\begin{tabular}{|l|l|l|l|}
\hline No & \multicolumn{1}{|c|}{ Nilai Rerata } & \multicolumn{1}{|c|}{ KK } & \multicolumn{1}{|c|}{ KE } \\
\hline 1. & Pre Test & 48.60 & 55.07 \\
\hline 2. & Post Test & 56.34 & 77.54 \\
\hline 3. & Peningkatan Nilai & 7.74 & 22.46 \\
\hline $4 . \quad \begin{array}{l}\text { Persentase Peningkatan } \\
\text { Nilai }\end{array}$ & $15.93 \%$ & $40.79 \%$ \\
\hline Nilai Gain (Post Test-Pre Test) & 7.74 & 22.46 \\
\hline Normalized Gain & 0.14 & 0.58 \\
\hline \multicolumn{2}{|l|}{ Interpretation } & Low & Medium \\
\hline
\end{tabular}

Tabel di atas menunjukkan bahwa siswa pada kelas eksperimen yaitu kelas yang menggunakan media pembelajaran LMS dikatakan mengalami peningkatan atau kemajuan hasil belajar secara signifikan yakni memperoleh persentase peningkatan nilai sebesar $40.79 \%$ dengan skor gain $\geq 0.3$ yakni mencapai 0.58 dengan kriteria sedang (medium). Sedangkan pada kelas kontrol yaitu kelas yang menggunakan media pembelajaran buku teks tidak mengalami peningkatan atau kemajuan hasil belajar secara signifikan, karena persentase peningkatan nilai yang diperoleh hanya mencapai $15.93 \%$ dengan skor gain $<0.3$ yakni 0.14 dengan kriteria rendah (low). Sehingga dapat disimpulkan bahwa penggunaan aplikasi Learning Management System pada jenjang Madrasah Aliyah dapat meningkatkan hasil belajar siswa secara signifikan.

\section{KESIMPULAN}

Berdasarkan penelitian yang telah dilakukan, maka kesimpulan dari penilitian ini adalah sebagai berikut:

1. Aplikasi Learning Management System pada jenjang Madrasah Aliyah yang dihasilkan memperoleh hasil penilaian User Acceptance Test (UAT) seluruh responden dengan rata-rata total rating scale sebesar 86.89\%, sehingga aplikasi LMS ini dinyatakan "Sangat Layak" untuk digunakan.

2. Hasil penilaian kelayakan media menunjukkan bahwa penilaian ahli materi berdasarkan dua aspek penilaian meliputi aspek pembelajaran, dan aspek pedagogi memperoleh skor $\mathbf{9 1 . 4 2 \%}$ dikategorikan sangat layak. Berdasarkan penilaian pengajar dari tiga aspek yaitu aspek pembelajaran, aspek pemrograman, dan aspek pedagogi memperoleh skor $\mathbf{8 4 . 9 5 \%}$ dikategorikan sangat layak. Adapun penilaian oleh siswa dari tiga aspek yaitu aspek pembelajaran, aspek pemrograman, dan aspek pedagogi memperoleh skor $\mathbf{8 4 . 2 9 \%}$ dikategorikan sangat layak.

3. Penggunaan aplikasi LMS sebagai media pembelajaran dapat meningkatkan hasil belajar siswa. Hal ini ditunjukkan berdasarkan hasil belajar siswa setelah diberikan media pembelajaran menggunakan aplikasi LMS mengalami peningkatan sebesar $\mathbf{4 0 . 7 9 \%}$ dengan skor $\mathrm{g} \geq 0.3$ yakni mencapai 0.58 untuk kategori sedang. 
Berdasarkan beberapa kesimpulan di atas dapat dinyatakan bahwa aplikasi Learning Management System pada jenjang Madrasah Aliyah berbasis Web-Enhanced Learning yang dihasilkan mencapai tujuan dari penelitian yakni aplikasi LMS ini sangat layak untuk digunakan, serta mampu mendukung proses pembelajaran yang dapat meningkatkan hasil belajar siswa secara signifikan.

\section{REFERENSI}

[1] S. Trisnaningsih, S. Suyanto, dan T. Rahayu, Pengembangan Learning Management System Quipper School pada Pembelajaran Materi Sistem Pertahanan Tubuh untuk Meningkatkan Motivasi dan Hasil Belajar Siswa Kelas XI di SMA Negeri 3 Yogyakarta, Jurnal Pendidikan Biologi. Vol. 5. No. 6. Hlm. 28-36, 2016.

[2] H. Batubara, Pembelajaran Berbasis Web dengan Moodle Versi 3.4. Yogyakarta: Deepublish, 2018.

[3] S. Wahyuliany, dan L. Rakhmawati, Pengembangan Media Pembelajaran E-Learning Web Enhanced Course Untuk Meningkatkan Hasil Belajar Siswa Pada Mata Pelajaran Teknik Listrik, Jurnal Pendidik. Teknik Elektro. Vol. 05. No. 3. Hlm. 581-587, 2016.

[4] A.Asyhari, dan R. Diani, Pembelajaran Fisika Berbasis Web Enhanced Course: Mengembangkan Web-Logs Pembelajaran Fisika Dasar I. Jurnal Inova Teknologi Pendidikan. Vol. 4. No. 1. Hlm. 13-25, 2017.

[5] P. Y. D. Mustafa, Rancang Bangun Aplikasi Learning Management System Berbasis Web Dengan Menggunakan Model SCORM Pada SMA Kartika. JSIKA. Vol. 7. No. 1. Hlm. 1-12, 2018.

[6] D. Darmawan, Pengembangan E-Learning Teori Dan Desain. Bandung: PT Remaja Rosdakarya, 2014.

[7] S. M. Alessi, dan S. R. Trollip. Multimedia for Learning: Methods and Development (3th Edition). 3th ed. New York: Pearson, 2000.

[8] B. Holmes, dan J. Gardner, E - Learning: Concept and Practice. London: Sage Publications, 2006.

[9] J. C. Granda, et. all, An Efficient Networking Technique for Synchronous E-Learning Platforms in Corporate Environments. Computer Communication. Vol. 33. Hlm. 1752-1766, 2010.

[10] Ristekdikti, Kebijakan Pendidikan Jarak Jauh dan E-Learning di Indonesia. Hlm. 13-14, 2016

[11] S. Koswara, Penyiapan Materi E-Learning. Hlm. 17-18, 2017.

[12] A. Andiani, Interaksi Dan Komunikasi Berbasis Teknologi Informasi Dan Komunikasi Dalam Pendidikan. Jutisi: Jurnal Ilmu Teknologi Informasi dan Sistem Informasi. Vol. 6. No. 1. Hlm. 1375-1382, 2017.

[13] "Activities-MoodleDocs." [Online]. Available: https://docs.moodle.org/38/en/Activities. [Accessed: 29-Nov2019].

[14] BSNP (Badan Standar Nasional Pendidikan). 2016. Standar Nasional: Standar Kompetensi Lulusan Pendidikan Dasar dan Menengah. [Online]. Available: http://bsnp-indonesia.org/wpcontent/uploads/2009/04/Permendikbud_Tahun2016_Nomor020_ Lampiran.pdf. [Accessed: 19-Jul-2019].

[15] L. E. Poerwati, dan S. Amri, Panduan Memahami Kurikulum 2013. Jakarta: PT Prestasi Pustakarya, 2013.

[16] Kosasih, Strategi Belajar dan Pembelajaran: Implementasi Kurikulum 2013. Bandung: Yrama Widya, 2014.

[17] R. A. Sukamto, dan M. Shalahuddin, Rekayasa Perangkat Lunak. Bandung: Informasi Bandung, 2016.

[18] R. Fajri, et. all, Strategi Sistem Testing dan Debugging. Banda Aceh: Universitas Ubudiyah Indonesia, 2016.

[19] E. C. Pramana, Pengujian User Acceptance Test. Bandung.

[20] Abdillah W. 2018. Metode Peneltian Terpadu Sistem Informasi. Jakarta: Andi Offset, 2017.

[21] Sugiyono, Metode Penelitian dan Pengembangan (Research and Development). Bandung: Alfabeta, 2015.

[22] S. Arikunto, dan A. C. Safruddin, Evaluasi Program Pendidikan. Jakarta: Bumi Aksara, 2009.

[23] I. Ernawati, Pengembangan Media Pembelajaran Interaktif pada Mata Pelajaran Administrasi Server di SMK Negeri 2 Depok
Sleman, 2017.

[24] B.Mulyadi, Pengembangan E-Learning pada Standarb Kompetensi Mengoperasikan Aplikasi Perangkat Lunak di SMK Negeri 7 Yogyakarta, 2017.

[25] S. Arikunto, Prosedur Penelitian: Suatu Pendekatan Praktik Jakarta: Rineka Cipta, 2013.

[26] D. E. Meltzer, The Relationship Between Mathematics Preparation And Conceptual Learning Gain in Physics: A Possible in 'Hidden Variable' in Diagnostic Pretest Scores. American Journal Physics. Hlm. 12-27, 2002. 